\title{
THE ANATOMICAL APPEARANCE IN RHEUMATIC TRICUSPID VALVE DISEASE
}

\author{
BY \\ ARTHUR HOLLMAN \\ From the Cardiac Department, University College Hospital \\ Received April 12, 1956
}

Although tricuspid stenosis has aroused interest since Duroziez (1868) pointed out its beneficial symptomatic effect on mitral lesions, there have been few detailed descriptions of the anatomy and function of the rheumatic tricuspid valve.

Lewis (1933) stated that " when stenosis is present it is slight, the thickened valve edge forming a fixed ring of considerable size." Taussig (1937) described a single case with a rigid valve opening $7 \mathrm{~cm}$. in circumference. Altschule and Budnitz (1940) studied two cases and stated that the deformity of the valve "causes a considerable degree of valvular incompetence and also varying degrees of stenosis." Smith and Levine (1942) found 32 examples of tricuspid stenosis in 340 autopsy cases of rheumatic heart disease $(9 \cdot 4 \%)$ and noted that the degree of stenosis was severe in 11, moderate in 11, and slight in 10. Aceves and Carrol (1947) studied 49 specimens of tricuspid disease and found " true stenosis" in 22 per cent, "pure insufficiency" in 54 per cent, and mixed lesions in 24 per cent; they did not describe the valve anatomy in any detail. Baggenstoss (1953) concludes that insufficiency and stenosis of the tricuspid valve are almost invariably associated, although one or the other may predominate.

The present study was undertaken in an attempt to obtain useful information prior to submitting a patient to tricuspid valvotomy.

\section{The Normal Tricuspid Valve}

The tricuspid orifice is placed in the medial and anterior part of the floor of the right atrium and, with the heart in its natural position, the orifice is almost vertical. Of the valve cusps (Fig. 1) the anterior (infundibular) is usually the largest and extends from close to the infundibulum to nearly the lateral margin of the orifice. The posterior (inferior, right) cusp lies in the right and posterior part of the opening. The septal cusp lies close to the septum and forms also part of the posterior margin of the valve; although usually described as the smallest $I$ have been impressed by the size of the septal cusp in normal hearts where it ranges from $3 \times 1 \mathrm{~cm}$. to $5 \times \frac{1}{2} \mathrm{~cm}$. Of the main papillary muscles (Fig. 1), the large anterior muscle is inserted into the adjacent margins of the antericr and posterior cusps, the smaller posterior into the posterior and septal cusps, and the small septal muscle into the septal and anterior cusps. The chordæ tendinæ and papillary muscles are thus attached almost in a ring around the tricuspid valve orifice (Fig. 1) and tether the edge of the valve to three different points of the compass.

The cavity of the right ventricle has a roughly three-sided pyramidal shape with the tricuspid orifice set in the right posterior wall. In the roof of the ventricle a thick muscular ridge, the crista supraventricularis (Fig. 2) separates the tricuspid orifice from the infundibulum and thus helps to divide the ventricular cavity into a posterior inflow tract and an anterior outflow tract. The tricuspid orifice projects into the cavity of the right ventricle rather like a funnel and is set an angle of roughly $60^{\circ}$ to the outflow tract. 


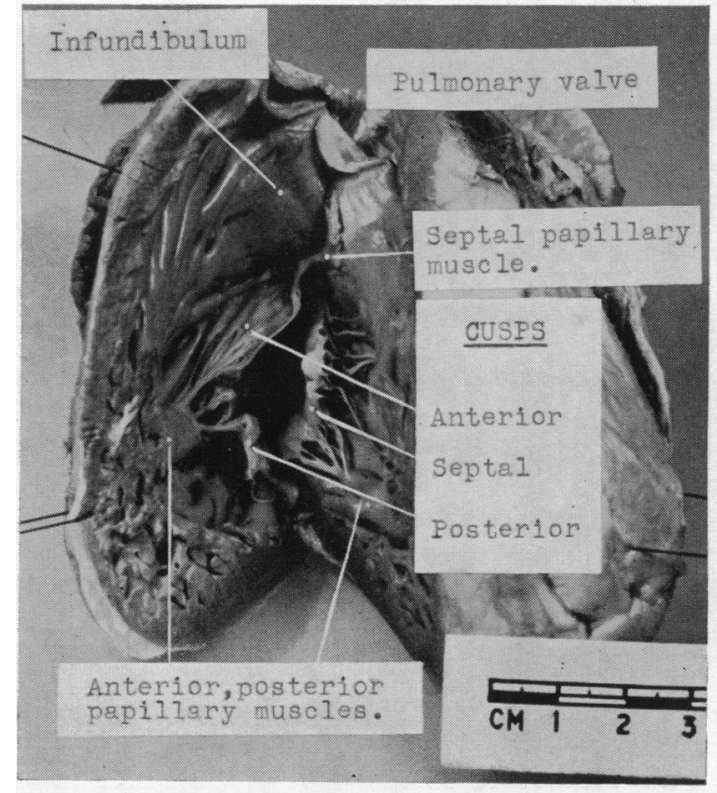

FIG. 1.-The normal tricuspid valve. The chordæ are attached to several points around the circumference of the valve and thus if the chordæ shorten or if the ventricle dilates the cusps will be pulled apart and incompetence will result. Shrinkage of the cusps will similarly lead to incompetence.

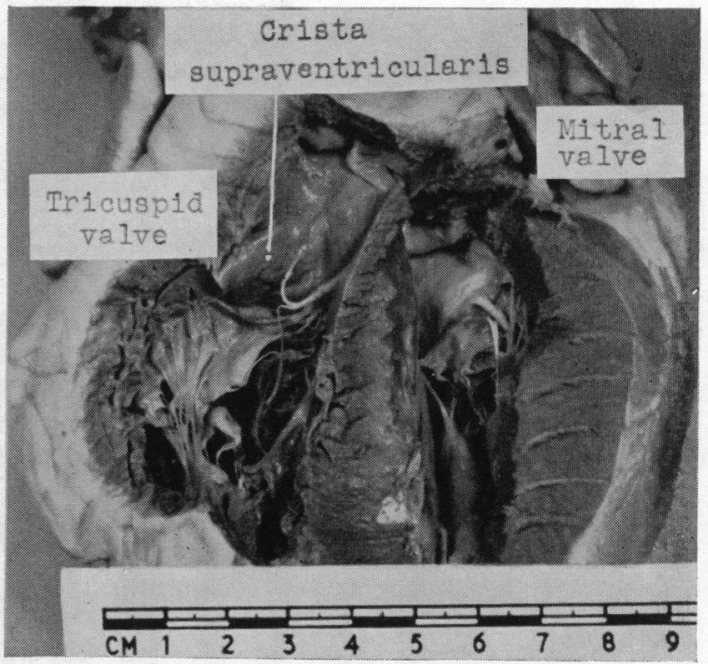

FiG. 2.-Dissection of a normal heart, fixed whole, showing that the tricuspid valve projects into the cavity of the ventricle whilst the mitral valve tends to be flush with the ventricular wall.

The function of the valve may be studied in the dead heart by distending the ventricular cavity with water (Brunton, 1906). Viewed from the right atrium, valve closure is seen to be effected by apposition of the atrial surfaces of the cusps almost at their margins (Fig. 3). The cusps bulge upwards like sails but are prevented from inversion by the chordæ which thus ensure competence of the valve.

The mitral valve, in contrast to the tricuspid, does not project forwards into the ventricular cavity but is set more or less flush with the wall (Fig. 2). In other words the inflow and outflow tracts of the left ventricle are parallel to each other, whereas on the right they are at an angle of about $60^{\circ}$. Therefore, by moving laterally in systole, the anterior cusp of the mitral valve can help to obliterate its inflow tract whilst no such action is possible with the tricuspid valve. In addition, according to Walmsley (1929), the two large mitral papillary muscles actually obliterate part of the inflow tract in systole: there is no comparable muscular action in the right ventricle. It is therefore apparent that the tricuspid valve is anatomically much weaker than the mitral as regards the prevention of incompetence.

\section{The Rheumatic Tricuspid Valve}

In order to obtain material for this study the museum of every London teaching hospital was visited and a total of 21 specimens of rheumatic tricuspid valve disease was found. The anatomical features of each valve were studied and in addition an attempt was made to assess what the probable function of the valve would have been during life. It is appreciated, however, that estimates of function based on fixed post-mortem material may be inaccurate.

Of the 21 valves, 5 had a valve length of $1.5 \mathrm{~cm}$. or less compared with the normal of $4 \mathrm{~cm}$. and therefore had a moderate or severe degree of stenosis. From the surgical viewpoint these valves are the most important of the group and will now be described. 
Moderate and Severe Tricuspid Stenosis. The sizes of the five valves in this group ranged from $\frac{3}{4} \times \frac{1}{4} \mathrm{~cm}$. to $1 \frac{1}{2} \times 1 \mathrm{~cm}$. The valve orifice, when viewed from the right atrium, appeared as a circular, oval or triangular hole in a large thin membrane. The orifice was central in four and towards the right and posteriorly in the fifth, where there was dominant fusion of the antero-septal commissure.

With regard to commissural fusion one might have expected from normal valve closure (Fig. 3) that the cusps would be adherent along their atrial surfaces. This type of fusion was in fact found in only one specimen in the entire series of 21 ; the three fused commissures in this valve are readily made out and have led to a severe degree of stenosis (Fig. 4). In the other four valves in

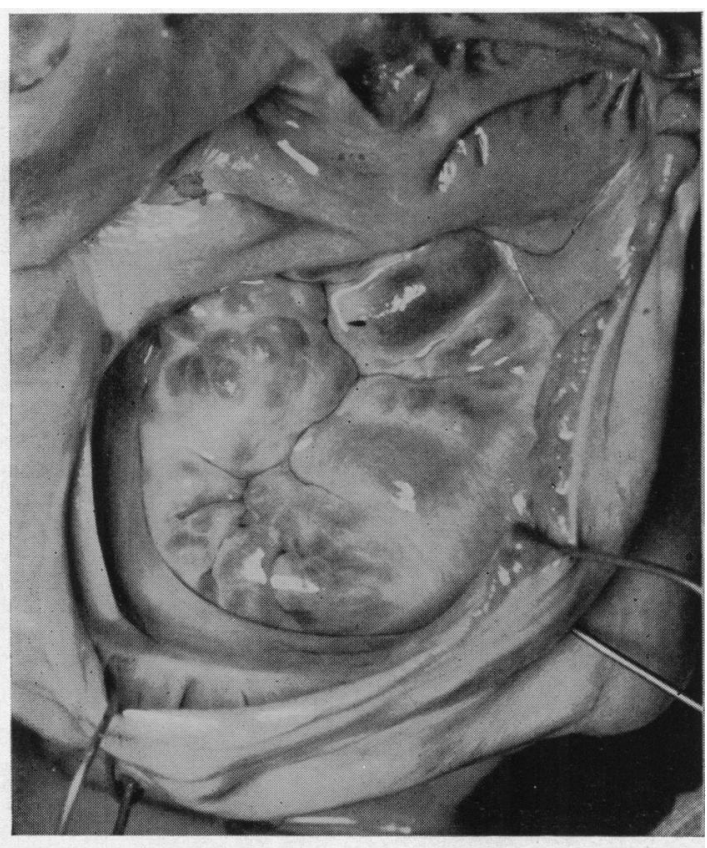

FIG. 3.-Normal tricuspid valve viewed from the right atrium, showing that closure is effected by contact of the cusps along their atrial surfaces. (Ventricle distended with water.)

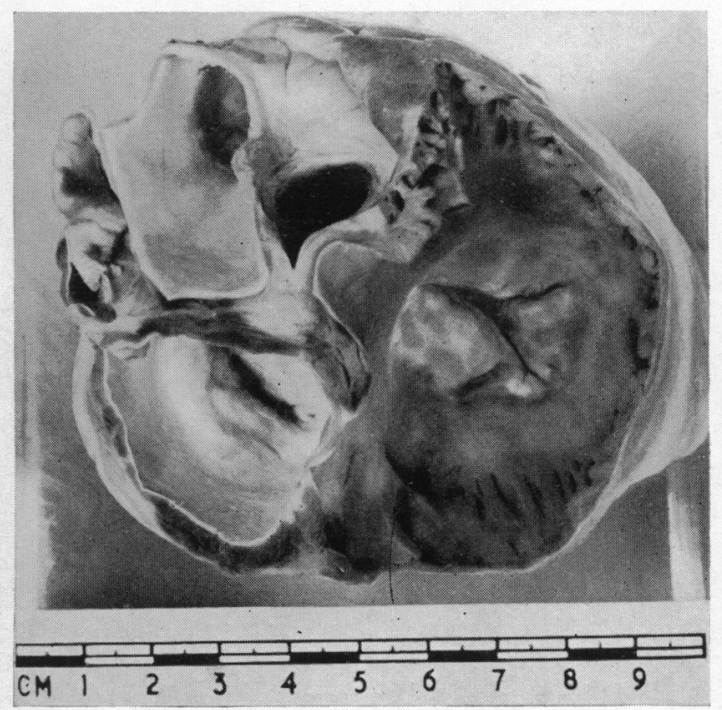

Fig. 4.-Heart divided transversely and viewed from above, showing severe tricuspid stenosis with fusion of the three commissures along their atrial surfaces. Note great dilatation of the right atrium and also the severe mitral stenosis. (Specimen 2393, Gordon Museum, Guy's Hospital. Reproduced by courtesy of Dr. Keith Simpson.)

this group the cusps were fused at their adjacent free edges thus producing a continuous valve curtain or shallow funnel, when viewed from the atrial aspect (Fig. 5). With one exception (Fig. 6) it was difficult to see the individual commissures and presumably it would have been difficult during life to palpate them from the right atrium. Well marked commissural fusion, extensive enough to have required division at valvotomy, involved all three commissures in one case, the antero-septal and antero-posterior in one case, the antero-septal and postero-septal in one case, and the anteroseptal alone in two cases.

Viewed from the ventricular aspect the valve appeared as a short funnel with an apparently rigid orifice in four of the five specimens (Fig. 7). The orifice was held open partly by its thickened rim and partly by the pull of the chordæ and papillary muscles from three opposing directions. This short funnel projected forwards into the cavity of the right ventricle and it is difficult to resist the conclusion that the rigid orifice must have permitted the regurgitation of blood through it during life. The probable degree of incompetence was judged to have been slight in one specimen and moderate in three. The fifth valve had dominant fusion of the antero-septal commissure with very little fusion of the other two (Fig. 6), and it seemed likely that in systole the posterior cusp 


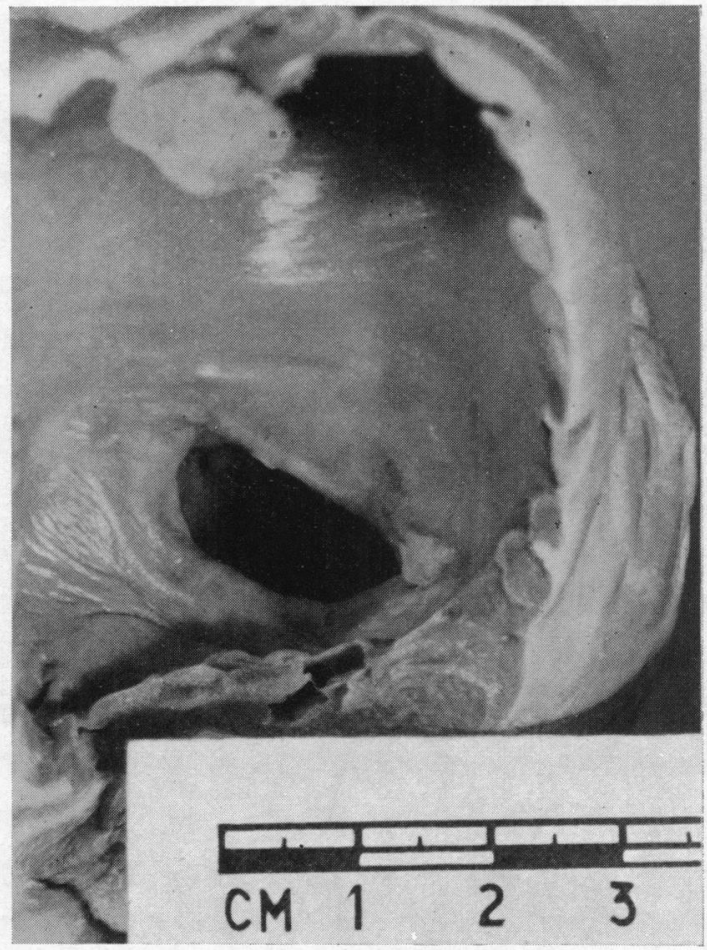

FIG. 5.-Valve viewed from above, showing the customary appearance in tricuspid stenosis. The valve has been converted into a smooth funnel in which it is almost impossible to make out the commissures.

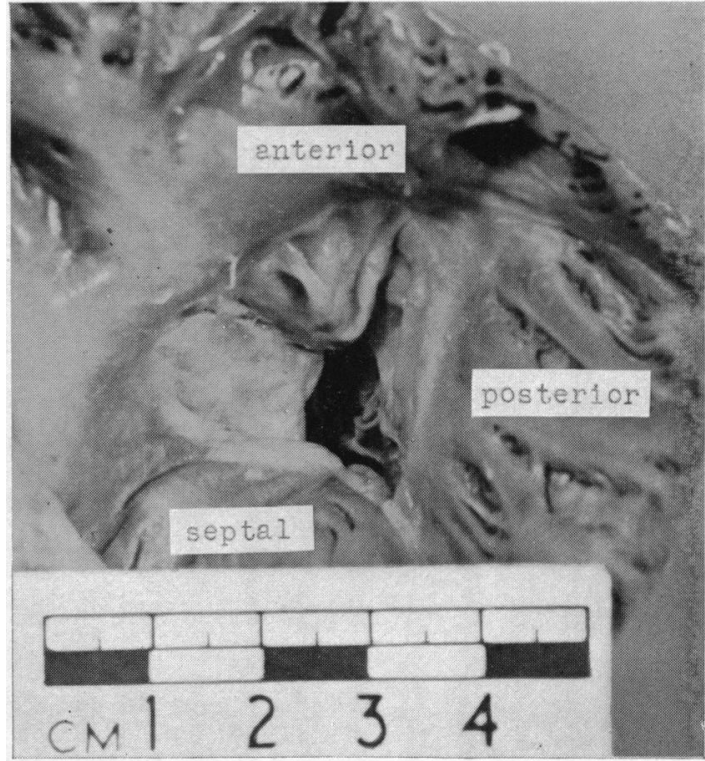

Fig. 6.-Extensive fusion of the antero-septal commissure has produced this fairly severe stenosis. The posterior cusp was probably able to close the orifice and thus prevent incompetence.

could fill the orifice and thus prevent incompetence. Thus of the five valves with moderate or severe stenosis probably only one was competent.

The valve cusps were smaller than normal, the anterior cusp for example averaged $14 \mathrm{~mm}$. from base to free margin compared with a normal of $20 \mathrm{~mm}$. The body of the cusp was sometimes thickened where chordæ were adherent to it, but on the whole the cusps were relatively thin and pliable. Calcification of the cusps was not seen. The free edge of the cusps, however, was considerably thickened in this group.

The chordæ tendinæ usually showed some shortening and thickening and the chordæ that gained insertion into the body of the cusp were sometimes adherent to it. But on the whole the chordæ were not much involved and only one specimen (Fig. 7) showed severe shortening of the chordæ. Cross fusion of the chordæ was never seen and thus sub-valvular stenosis was likewise absent.

Slight or No Stenosis. Of the remaining 16 specimens, 8 had slight stenosis with a valve length of 1.6 to $2.5 \mathrm{~cm}$. and 8 had virtually no stenosis. The general features of these valves were similar to those described for the tightly stenotic ones. The cusps were always fused at their adjacent free edges and in some instances as a result the commissure was so indistinct that its position could only be made out from the insertion of the chordæ.

Eight of the specimens had well-marked fusion of only one commissure which was the anteroseptal in seven and the postero-septal in one, and a further specimen had fusion of both. The majority of the 16 specimens looked as though they were incompetent during life and in 8 of them the incompetence was probably considerable in degree.

Involvement of Other Valves. The mitral valve was diseased in all the 21 specimens. In two- 


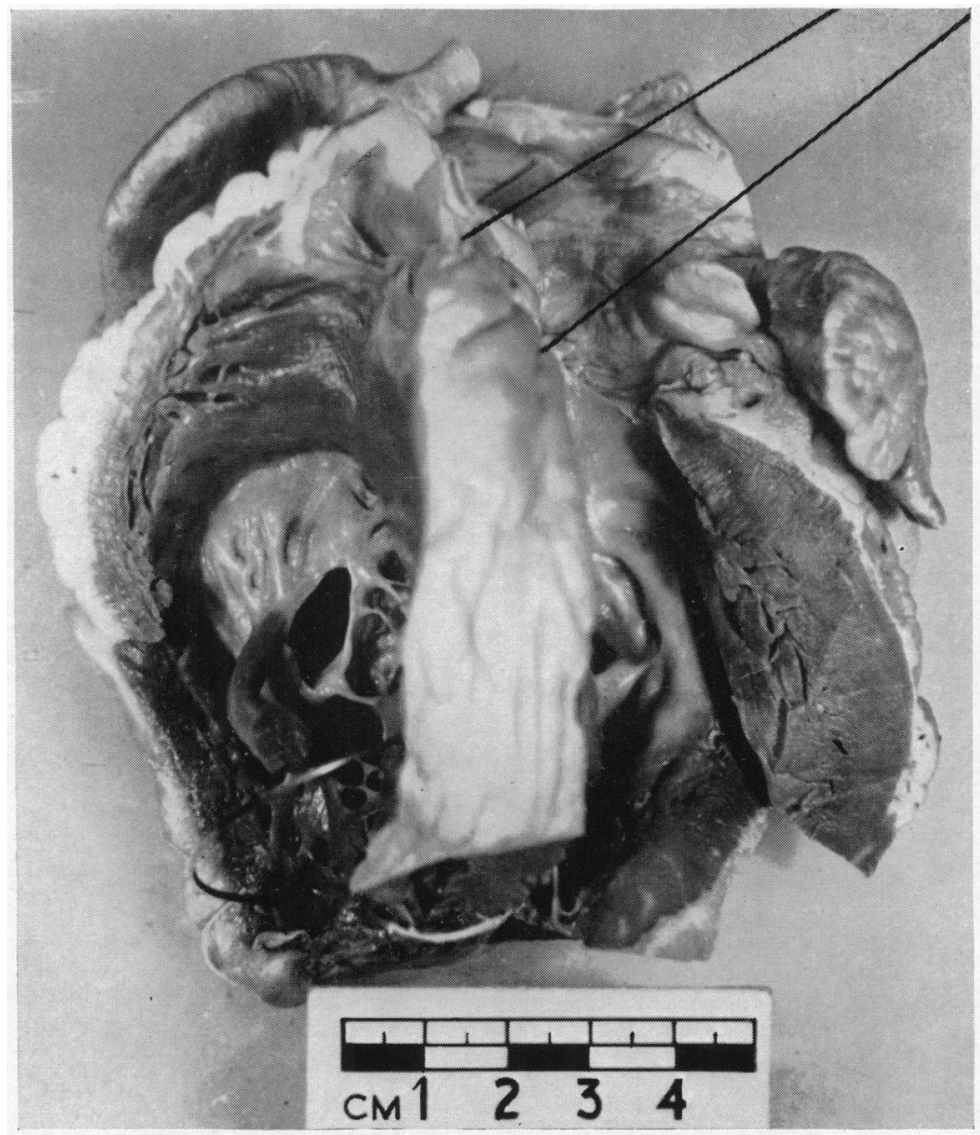

FIG. 7.-Fairly severe tricuspid stenosis with a rigid incompetent valve orifice. The degree of chordal involvement is unusually severe. Compared with the stenosed mitral valve the position of the tricuspid orifice clearly favours incompetence.

thirds it presented the typical appearance of a tight pure stenosis whilst in 6 specimens it appeared to be both stenotic and incompetent, and in one to be dominantly incompetent.

Aortic valve involvement was found in 14 specimens, being moderate to considerable in degree in 12 of these. It was unaffected in 3 and was absent from the specimen in the remainder.

In the specimens studied the mitral valve always contrasted strongly with the tricuspid valve. The mitral valve usually presented the typical appearance of tight mitral stenosis and the valve was well protected from incompetence by a large anterior cusp which was often lengthened by fusion with the chordæ. As can be seen from Fig. 7 this state of affairs was very different from that with the stenosed tricuspid valve where a rigid orifice projected into the ventricular cavity and favoured incompetence. The normal valve anatomy was thus mirrored in the diseased valves.

A Calcified Tricuspid Valve. The heart from a man, aged 46, who died with pulmonary valvular stenosis shows the only calcified tricuspid valve I have seen. The valve cusps were thickened especially at their margins and contained nodules of calcium and the chordæ were shortened. The pulmonary valve orifice measured $3 \mathrm{~mm}$. in diameter and the right ventricle was as thick as the left. The mitral and aortic valves were normal. This may be an example of congenital tricuspid valve disease, or possibly the changes may be secondary to the long continued high closing pressure to which the valve was subject. Rheumatic involvement seems unlikely. 


\section{DisCUSSION}

The difference in anatomy and function between the mitral and tricuspid valves has been recognized since William Harvey (1628) wrote, "In the left ventricle therefore, and in order that the occlusion may be the more perfect against the greater impulse, there are only two valves, like a mitre, ... and produced into an elongated cone, so that they . . . touch to their middle. . . . thus it is that these mitral valves excel those of the right ventricle in size and strength and exactness of closing." King, in 1837, found that distension of the ventricle with water always closed the mitral valve firmly whilst the tricuspid often presented a considerable reflux. He thought that the tricuspid valve being weak could act as a safety valve to the right ventricle. The present study has confirmed these anatomical and functional observations on the normal valve and has shown that similar considerations apply to the valve when affected by rheumatic disease.

In this series the ratio with severe, moderate and slight affections was 24,38 , and 38 per cent, a figure similar to that of Smith and Levine (1942). Tricuspid incompetence was thought to be slight or absent in 38 per cent, moderate in 28 per cent, and considerable in 38 per cent. The conclusion from this study that incompetence is a common accompaniment of stenosis of the tricuspid valve is open to the objection that function cannot be accurately deduced from anatomical appearance; but support for this deduction is found in the reported cases of tricuspid valvotomy of which only 25 per cent ( 2 out of 8 ) had competent valves at operation (Hollman, 1956).

The antero-septal commissure was fused in this series in 14 instances compared with 6 fusions of the postero-septal and 4 of the antero-posterior commissure (excluding slight degrees of fusion). This dominance is probably due to the fact that the angle between the anterior and septal cusps is much narrower than at the other two commissures and thus these cusps can more readily become adherent to each other (Fig. 1).

\section{SUMMARY}

The anatomy of the normal tricuspid valve shows it to be vulnerable to incompetence especially when it is compared with the mitral valve.

Of 21 specimens of rheumatic tricuspid valve disease there were 5 with well marked stenosis. The valve orifice in four of these five formed a short rigid funnel which was probably incompetent during life, but was competent in the fifth. The fused commissures, with a few exceptions, were difficult to see from the atrial aspect and presumably would have been difficult to feel at valvotomy during life. Eight of the sixteen valves with slight or no stenosis were probably incompetent to a considerable degree.

The stenosed mitral valve usually contrasted strongly with the stenosed tricuspid valve in the same specimen in that the mitral valve was clearly much better protected from incompetence.

I am most grateful to the curators of the museums of the London teaching hospitals for permitting me to study and describe specimens in their care. It is a pleasure to thank Dr. Kenneth E. Harris for his help in the preparation of this paper. The photographs were taken by Mr. A. C. Lees and Mr. A. Bligh.

\section{REFERENCES}

Aceves, S., and Carrol, R. (1947). Amer. Heart J., 34, 114.

Altschule, M. D., and Budnitz, E. (1940). Arch. Path., 30, 7.

Brunton, L. (1906). Collected Papers on Circulation and Respiration. London, Macmillan. First series, p. 537.

Baggenstoss, A. (1953). In Pathology of the Heart, ed. by Gould, S. E. C. C. Thomas, Springfield, Ill.

Duroziez, P. L. (1868). Gaz. d. hôp., 41, 310.

Harvey, W. (1628). The Works of William Harvey. Sydenham Society, London, 1847, p. 80.

Hollman, A. (1956). Lancet, 1, 535.

King, T. W. (1837). Guy's Hosp. Rep., 2, 104.

Lewis, T. (1933). Diseases of the Heart. London, Macmillan.

Smith, J. A., and Levine, S. A. (1942). Amer. Heart J., 23, 739.

Taussig, B. L. (1937). Amer. Heart J., 14, 744.

Walmsley, T. (1929). Quain's Elements of Anatomy, 11 th ed., Vol. IV, Part III. Longmans, London. 